\title{
A Look at Medical Secrecy from the Perspective of Russian “Medical” Legislation
}

\author{
Igor B Boyko* \\ ${ }^{1}$ FSBOU VO Ryazan State Medical University, Academician I.P. Pavlov of the Ministry of Health of the Russian Federation, Ryazan, \\ Russia
}

${ }^{2}$ Professor of Hertology, Pathological Anatomy and Medical Genetics of the Russian Ministry of Health, Ph.D.Medical Sciences, Russia

*Corresponding author: Igor B Boyko, Doctor of Medical Sciences, Professor, Lawyer, Ryazan State Medical University named after Academician I.P. Pavlova, Ryazan, Russia

\begin{tabular}{|c|c|}
\hline ARTICLE INFO & ABSTRACT \\
\hline Received: 慧 September 10, 2020 & $\begin{array}{l}\text { Citation: Igor B Boyko. A Look at Medical Secrecy from the Perspective of Russian } \\
\text { "Medical" Legislation. Biomed J Sci \& Tech Res 30(4)-2020. BJSTR. MS.ID.004992. }\end{array}$ \\
\hline
\end{tabular}

\section{Opinion}

In the medical secret, as it is known, is the most important and obligatory elementmedical care, the essence of which is the concealment of medical information by the doctor in relation to the patient.Its adherence is one of the basic principles of health care, while the opposite effect can lead to serious legal consequences. Today, medical secrecy should be attributed to concepts that have lost their original meaning, usually associated with the name Hippocratic.This loss can be seen in the example of the current Russian health legislation, the Federal Law on the Basics of Citizens' Health in the Russian Federation21.11.2011.No323-Fz. It has a well-known and unambiguous understanding of medical secrecy, as well as its observance, in many positions does not correspondFor example, the law states that the number of subjects responsible for the observance of medical secrecy (in particular, information systems operators) have been expanded.But such an increase in the number of informed persons is highly undesirable because of the risk of an increase in disclosure[1].

This article, based on the material of modern Russian health legislation, examines the main provisions concerning the concept of medical secrecy and its compliance.

a) Comparative analysis of the currentlegislation with theprevious one (Basics of the legislation of the Russian Federation "On the protection of citizens' health" from22.07.1993 No5487-1) [2] shows the great interest of the legislator in the issue of compliance with medical secrecy.This opinion is based on a comparison of the references to the term "medical secret."

b) The term "medical secrecy" is legal, as evidenced, in particular, by its definition in the legislation - "a combination of information, including data on the fact of the citizen's request for medical care, his state of health and diagnosis, as well as other information obtained during his medical examination and treatment."To this definition of medical secrecy, the legislator adds more information about the patient (victim, deceased) in connection with the provision of pre-medical care (at the scene of the accident). The common view of the term "medical secrecy" as medical seems incorrect, although the latter is related to medical activities, medical and non-medical data.Medical secrecy is a concept that has to do with medical activity, but still goes beyond "medical" competence[2].

c) Medical secrecy refers to "lifetime" and "posthumous" status, as it extends to the time that comes after the death of a person.In the preceding "medical" legislation, medical secrecy could have only "lifetime" status.

d) In addition to doctors, other persons with medical and non-medical education (from among those directly related to medical care) are also involved in the observance of medical 
secrecy.Already this circumstance allows to consider the name of the term "medical secret" (similar - "medical secret) quite conditional. The term "medical secrecy" could well be replaced by the term "confidentiality of patient information" or "confidentiality in medical relations".Any of the proposed names more accurately expresses the concept, as, on the one hand, indicatesan individual who receives medical care or who has sought medical care, regardless of whetherhe has a medical condition and an edict, on the other hand, it reflectsthe essence of the information retained.

e) Information about people who receive medical services is limited information and is subject toThis provision demonstrates the not only about the high social significance of the information, but also about the seriousness of the legal consequences associated with their disclosure.The legislator has also acted on information relating to persons who provide. Thus, current health legislation treats the protection of the rights to preserve information in the conduct of medical activities as for those who providehealth services, as well as for those to whom these medical services are provided.

f) The list of grounds allowing the provision of medical secrets without the consent of the citizen or his legal representative is too broad.Such an extension cannot affect the relationship that determinesthe concept of "medical mystery" because it seriously narrows the "space" associated with it.The meaning of today's concept of "medical secrecy" is connected not only with the significant narrowing of "non-disclosure" resembling the abbreviation of "shagreen skin", but also with the very essence of this social phenomenon.If in the classical sense the doctor's secret is a secret of the doctor, and it remained for a long time, today - it can be talked about as a fairly conditional and in fact constitutes protection of confidential information of a private medical nature.

Medical secrecy in both the "Soviet" and "post-Soviet" periods has never been distinguished by absolutism.This is said to be exceptions to it, which allowed to provide information that constitutes medical secrecy, without the consent of the citizen or his legal representative.At the same time, if in the "Soviet" period they corresponded to two positions, in the "post-Soviet" - already 10.There is a significant increase in thepositions associated with exceptions to medical secrecy, hence the medical secret in our country losesits "mystery" and, therefore, its significance.Strangely, the observed increase in attention to medical secrecy at the level of the law took place against the background of the growing position of exclusion from medical secrecy, the loss of its secrecy.

\section{References}

1. (2011) Federal law on the basics of protecting the health of citizens in the Russian Federation 21,11/2011.N323-Fz. International Labour organization.

2. (1993) The basics of the Legislation of the Russian Federation On the Protection of Citizens Health 5487-5491.

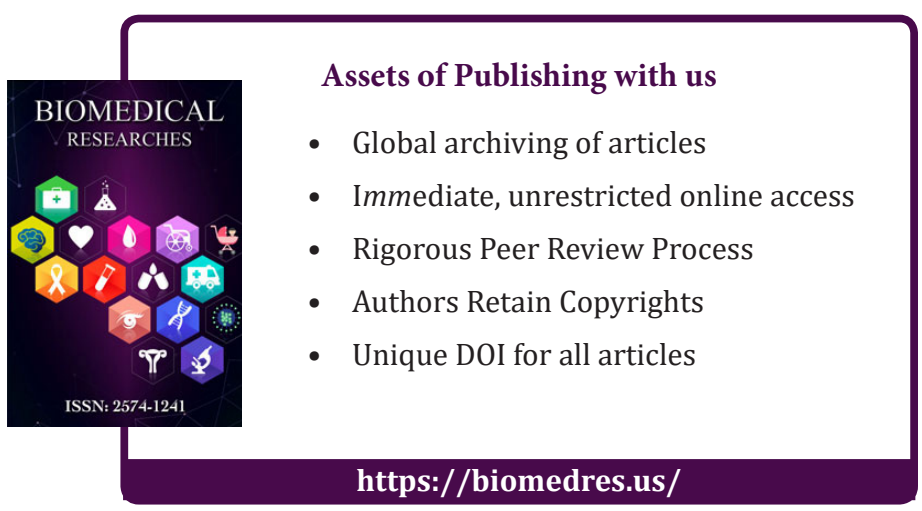

